\title{
Iron Status and Dietary Patterns of Collegiate Female Distance Runners
}

Case Study

Rachel Walny ${ }^{1}$, Carrie Hamady ${ }^{2}$, Wan Shen ${ }^{2}$, Todd Keylock ${ }^{3}$

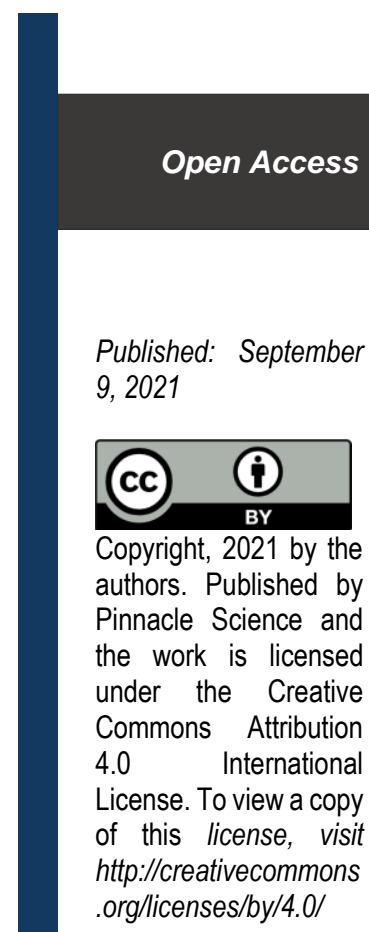

Journal of Exercise and Nutrition: 2021, Volume 4 (Issue 3): 17

ISSN: $2640-2572$
${ }^{1}$ Bowling Green State University, Obio/United States, School of Human Movement, Sport, and Leisure Studies, Department of Public and Allied Health

${ }^{2}$ Bowling Green State University, Obio/United States, Department of Public and Allied Health

${ }^{3}$ Bowling Green State University, Ohio/United States, School of Human Movement, Sport, and Leisure Studies

\begin{abstract}
Introduction: Iron is in oxygen transport which is important for athletic performance. Many female distance runners struggle to maintain adequate iron status through diet alone and rely on iron supplementation.

Methods: Interviews were conducted with eight members of the women's cross country team at a division I university to assess dietary patterns and behaviors related to iron status. This information, along with food records and serum ferritin levels, were analyzed qualitatively for trends with a focus on iron intake, total energy intake, and food components that enhance and inhibit iron absorption.

Results: All participants took an iron supplement at the time of the study. All but one had experienced poor iron status currently or in the past. Most participants did not meet dietary iron, Vitamin E, or estimated energy requirements. Half of the participants expressed an attempt to increase iron intake in response to higher training loads. Half attempted to increase intake in response to a low ferritin result or iron deficiency symptoms.

Conclusions: Consistently low energy and iron intake among participants indicated the likelihood of a relationship with poor iron status and/or reliance on supplementation. The most common motivation for increasing iron intake was the prevention of symptoms.
\end{abstract}

Key Words: Ferritin, athletes, energy

Corresponding author: Todd Keylock, tkeyloc@bgsu.edu

\section{Introduction}

Iron is an essential micronutrient for several functions within the body, including in oxygen transport. ${ }^{1}$ It is involved in the reaction that binds oxygen to hemoglobin in the blood and myoglobin in the muscle..$^{2-3}$ Several factors impact iron status in the body. For instance, heme/animal-based iron and non-heme/plant-based iron are absorbed differently. ${ }^{1}$ Other components of the diet can either promote or inhibit iron absorption. Serum ferritin is generally 
accepted as the ideal measure of iron status for several reasons: it has the highest sensitivity and specificity, and it can be used to detect iron deficiency earlier than other measures because it is directly proportional to body iron stores. ${ }^{2,7}$

Athletes can be susceptible to iron deficiency for several reasons: gastrointestinal blood loss, sweat loss, increased red blood cell turnover, thermal hemolysis, and foot strike hemolysis, which is of particular concern for distance runners. ${ }^{3,}$ ${ }^{5}$ Another risk factor specific to endurance runners is the intensity and duration of exercise, which exacerbates these risk factors. ${ }^{8}$

Females are at a higher risk for iron deficiency than males, due in large part to iron lost through menstruation. $3,6,9-11$ Therefore, the purpose of this study was to examine the diets of female Division I Cross-Country runners with a history of poor iron status managed by iron supplementation to assess common themes that may explain this phenomenon, as well as examine common attitudes and behaviors that may contribute to poor iron status and/or reliance on supplementation.

\section{Methods}

\section{Participants}

Recruitment emails were sent to all members of a division I women's cross-country team during the Fall of 2020. After consent, participants were asked for their iron supplementation status including duration, current usage, and dose. Members of the team are usually instructed by the team physician to take an iron supplement if their ferritin level is at or below $30 \mu \mathrm{g} / \mathrm{L}$. All volunteers were taking iron supplements at the time of the study and were included. The study was approved by the Institutional Review Board.

\section{Protocol}

Each participant met twice with the researcher. A time and date for the first meeting were established via email. Participants met with the researcher in a private room on campus. The participant was given the informed consent form at the beginning of the first meeting. After consent, the participant's age was self-reported and height and weight were obtained using a stadiometer and a digital scale, respectively. The researcher explained how to complete a threeday food record including two weekdays and one weekend day with the aid of the "Serving Size Card."13 Participants were asked to include everything that they consumed, including food, drinks, and supplements, including portion size. For supplements, participants were asked to record the nutrient(s) and dosage. A time and date were then established for the second meeting, which took place approximately one week later.

At the second meeting, the participant's three-day food record was reviewed for accuracy and correct interpretation by the researcher. Audio recording was then started, and the reviewer proceeded with the interview script regarding the participants' attitudes and behaviors surrounding their dietary intakes, as well as any clarifying questions based on the participant's responses. While listening, the researcher took detailed notes. Lastly, the women's Cross Country Athletic Trainer provided the most recent ferritin level for each participant via email.

\section{Analysis}

Estimated energy requirements (EER) were calculated for each participant using the Mifflin St. Jeor equation which is a common equation used in other studies to estimate resting metabolic rate (RMR). ${ }^{14-15}$ This equation requires the participant's weight in kilograms $(\mathrm{kg})$, height in centimeters $(\mathrm{cm})$, and age in years and provides RMR in units of kilocalories per day (kcal/day). The participant's physical activity level (PAL) was then factored into her energy requirement using an activity factor of 2.0, which was multiplied by the value for RMR to estimate total energy expenditure (TEE). ${ }^{16}$ This activity factor accommodates for vigorous endurance training. This equation was used rather than prediction equations that factor in running paces because these athletes' paces vary significantly from day to day. ${ }^{17}$ Therefore, the Mifflin St. Jeor equation provides a more general idea of energy requirements over an extended period of training. ${ }^{17}$

Food records were analyzed using Axxya Systems NutritionistPro ${ }^{\mathrm{TM}}$, version 6.2. Total energy intake, iron, and enhancers/inhibitors of iron absorption were assessed using this program. Average number of servings of coffee and tea were assessed since these beverages are common sources of iron absorption inhibiting polyphenols. ${ }^{1,4,6}$ Iron supplements were not included in the diet analysis, as the goal was to analyze potential gaps in the participants' dietary intakes independent of iron supplementation. 
Each participant's total energy intake was compared to her EER. Total iron intake was assessed based on whether each participant met the Recommended Daily Allowance (RDA) for iron of $18 \mathrm{mg}$ iron per day for women aged 19-30 years. ${ }^{12}$ The intake of the remaining nutrients was compared across participants to assess whether themes existed in the consumption of certain nutrients or lack thereof. The number of participants in the study was too small for statistical analysis, so these data were analyzed qualitatively for trends suggesting dietary explanations that may indicate why these runners require iron supplementation to maintain adequate ferritin levels.

The participants' attitudes and behaviors regarding dietary habits and ferritin levels were assessed using scripted interview questions. The researcher took detailed notes of responses during the interview, then reviewed the recordings to add missing details to the notes. This technique is recommended when resources (professional transcriber, qualitative data analysis software) are limited. ${ }^{18}$

Once detailed notes of each interview were complete, the researcher reviewed the notes for common themes/patterns between the participants' responses. ${ }^{18}$ These were organized into categories that emerged from the responses and sorted based on the research question that each category addressed. ${ }^{19}$ The validity of the findings were established using methods related to qualitative data. The first was triangulation. ${ }^{20}$ This required sorting through the data to find themes - particularly the convergence of themes across participants and methods. ${ }^{20}$ The second was researcher reflexivity, which requires the researcher to self-disclose any assumptions, beliefs, or biases that may affect the interpretation of the findings. ${ }^{20}$

\section{Results}

Eight athletes volunteered to participate in the study. All eight met the requirements for participation, were taking an iron supplement and had undergone ferritin testing in August 2020, just prior to the start of cross-country season and this study. Tables 1-4 provide information regarding basic participant characteristics, current and history of supplement usage, training, energy intake, and nutrient intake. It should also be noted that participants reported having five to seven running days per week and performed some sort of aerobic training (bike or elliptical) on non-running days.

Table 1. Participant Characteristics

\begin{tabular}{l|cccccc}
\hline \multicolumn{1}{c}{ PARTICIPANT } & $\begin{array}{c}\text { ACADEMIC } \\
\text { YEAR }\end{array}$ & $\begin{array}{c}\text { AGE } \\
\text { (YEARS) }\end{array}$ & $\begin{array}{c}\text { HEIGHT } \\
\text { (CM) }\end{array}$ & $\begin{array}{c}\text { WEIGHT } \\
\text { (KG) }\end{array}$ & $\begin{array}{c}\text { BMI } \\
\text { (KG/M }^{2} \text { ) }\end{array}$ & $\begin{array}{c}\text { FERRITIN } \\
\text { LEVEL (MG/L) }\end{array}$ \\
\hline SUBJECT A & Senior & 21 & 166.0 & 56.7 & 20.6 & 23.5 \\
SUBJECT B & Freshman & 19 & 167.0 & 58.1 & 20.8 & 41.5 \\
SUBJECT C & Senior & 21 & 157.5 & 57.7 & 23.3 & 25.0 \\
SUBJECT D & Sophomore & 19 & 163.0 & 55.8 & 21.0 & 50.4 \\
SUBJECT E & Freshman & 19 & 171.0 & 61.0 & 20.9 & 24.6 \\
SUBJECT F & Senior & 21 & 162.0 & 50.4 & 19.2 & 30.7 \\
SUBJECT G & Sophomore & 20 & 167.0 & 60.8 & 21.8 & 11.9 \\
SUBJECT H & Junior & 21 & 168.0 & 54.2 & 19.2 & 34.1
\end{tabular}

Table 2. Supplement Usage

\begin{tabular}{|c|c|c|c|}
\hline PARTICIPANT & FORMC & DOSAGE & HISTORY/DURATION OF SUPPLEMENT USAGE \\
\hline SUBJECT A & Pill & $\begin{array}{l}65 \mathrm{mg}(2 \mathrm{X} \\
\text { daily) }\end{array}$ & 3 years \\
\hline SUBJECT BA & Pill (multivitamin) & $18 \mathrm{mg}$ (daily) & Since before high school \\
\hline SUBJECT CB & Liquid & $15 \mathrm{~mL}$ (daily) & $\begin{array}{c}\text { Previously } 3-4 \text { pills per day ( } 65 \mathrm{mg} \text { each) starting } \sim 5 \text { years prior } \\
\text { to study }\end{array}$ \\
\hline SUBJECT D & Pill & $\begin{array}{l}65 \mathrm{mg}(2 \mathrm{X} \\
\text { daily) }\end{array}$ & $<1$ year \\
\hline SUBJECT EB & Pill & $\begin{array}{l}65 \mathrm{mg}(2 \mathrm{X} \\
\text { daily) }\end{array}$ & No previous supplementation \\
\hline SUBJECT F & Pill & $\begin{array}{l}65 \mathrm{mg}(2 \mathrm{X} \\
\text { daily) }\end{array}$ & $\begin{array}{l}\text { Starting } 3 \text { years prior (2017); switched to liquid iron for } \sim 1 \text { year } \\
\text { (2018-2019) }\end{array}$ \\
\hline SUBJECT GB & Liquid & $15 \mathrm{~mL}$ (daily) & Previously 2 pills per day (65 $\mathrm{mg}$ each) starting 1 year prior \\
\hline SUBJECT H & Pill & $\begin{array}{l}65 \mathrm{mg}(2 \mathrm{X} \\
\text { daily) }\end{array}$ & Lower dosage in high school; 4X daily from Fall 2018-2019 \\
\hline
\end{tabular}


${ }^{\mathrm{C}}$ Brand names of the supplements were not available

Table 3. Estimated Energy Requirement Versus Actual Energy Intake

\begin{tabular}{l|ccc}
\hline PARTICIPANT & $\begin{array}{c}\text { EER } \\
\text { (KCAL/DAY) }^{\mathbf{A}}\end{array}$ & $\begin{array}{c}\text { ACTUAL ENERGY INTAKE } \\
\text { (KCAL) }^{\mathbf{B}}\end{array}$ & $\begin{array}{c}\text { PERCENTAGE OF EER } \\
\text { CONSUMED (\%) }\end{array}$ \\
\hline SUBJECT A & 2,677 & 1,568 & 58.6 \\
SUBJECT B & 2,738 & 1,947 & 71.1 \\
SUBJECT C & 2,591 & 1,911 & 73.8 \\
SUBJECT D & 2,642 & 2,727 & 103.2 \\
SUBJECT E & 2,846 & 1,852 & 65.1 \\
SUBJECT F & 2,501 & 1,883 & 75.3 \\
SUBJECT G & 2,781 & 1,612 & 58.0 \\
SUBJECT H & 2,652 & 2,574 & 97.1
\end{tabular}

${ }^{A}$ Estimated Energy Requirement $(\mathrm{EER})=\mathrm{RMR}(10 \mathrm{x}$ weight $[\mathrm{kg}]+6.25 \mathrm{x}$ height $[\mathrm{cm}]-5 \mathrm{x}$ age [years] -161$) \mathrm{x}$ activity factor of 2.0 (rounded to the nearest kcal)

${ }^{B}$ Average of three-day intake

Table 4. Intake of Iron and Enhancers/Inhibitors of Absorption (Excluding Supplements)

\begin{tabular}{|c|c|c|c|c|c|c|c|c|}
\hline PARTICIPANT & $\begin{array}{l}\text { IRON } \\
\text { (MG) }\end{array}$ & $\begin{array}{c}\text { VIT. } \\
\text { C } \\
\text { (MG) }\end{array}$ & $\begin{array}{c}\text { VIT. } \\
\text { E } \\
(\mathrm{MG})\end{array}$ & $\begin{array}{c}\text { BETA } \\
\text { CAROTENE } \\
\text { (VIT. A) } \\
\text { (MCG RAE) }\end{array}$ & $\begin{array}{l}\text { CYSTINE } \\
\text { (MG) }\end{array}$ & $\begin{array}{l}\text { METHIONINE } \\
\text { (MG) }\end{array}$ & $\begin{array}{l}\text { CALCIUM } \\
\text { (MG) }\end{array}$ & $\begin{array}{c}\text { COFFEE } \\
(200 \mathrm{ML} \\
\text { SERVINGS) }\end{array}$ \\
\hline SUBJECT A & 6.7 & $79.0^{\mathrm{A}}$ & $16.9^{\mathrm{A}}$ & $155.3(445.3)$ & $477.1^{\mathrm{A}}$ & $714.3^{\mathrm{A}}$ & 325.3 & 0.5 \\
\hline SUBJECT B & 12.3 & $91.8^{\mathrm{A}}$ & 6.5 & $\begin{array}{c}6926.2 \\
(957.7)^{\mathrm{A}}\end{array}$ & $1090.2^{\mathrm{A}}$ & $2240.4^{\mathrm{A}}$ & 626.8 & 0 \\
\hline SUBJECT C & 16.8 & $90.8^{\mathrm{A}}$ & 9.4 & $1211.1(274.8)$ & $620.6^{\mathrm{A}}$ & $1032.9^{A}$ & 643.9 & 1 \\
\hline SUBJECT D & 16.0 & 51.7 & 6.6 & $\begin{array}{c}3503.7 \\
(1097.1)^{\mathrm{A}}\end{array}$ & $552.4^{\mathrm{A}}$ & $1246.9^{\mathrm{A}}$ & $1325.8^{\mathrm{A}}$ & 1 \\
\hline SUBJECT E & 10.6 & $166.4^{\mathrm{A}}$ & 5.1 & $1301.6(349.8)$ & $331.1^{\mathrm{A}}$ & $716.8^{A}$ & 854.1 & 0 \\
\hline SUBJECT F & 12.1 & 36.8 & 5.9 & $581.5(711.6)^{A}$ & $440.7^{\mathrm{A}}$ & $1063.1^{\mathrm{A}}$ & $1111.5^{\mathrm{A}}$ & 1.5 \\
\hline SUBJECT G & 16.2 & $136.5^{\mathrm{A}}$ & 13.3 & $\begin{array}{c}8222.5 \\
(1312.3)^{\mathrm{A}}\end{array}$ & $558.6^{\mathrm{A}}$ & $1159.3^{A}$ & $1461.0^{A}$ & 0.5 \\
\hline SUBJECT H & $20.5^{\mathrm{A}}$ & $92.0^{A}$ & $23.1^{\mathrm{A}}$ & $\begin{array}{c}2788.9 \\
(1619.0)^{\mathrm{A}}\end{array}$ & $539.6^{\mathrm{A}}$ & $1087.7^{\mathrm{A}}$ & $1379.0^{\mathrm{A}}$ & 0 \\
\hline
\end{tabular}

${ }^{\mathrm{A}}$ Met requirements

Interviews with the participants provided further insight into dietary intakes. All but Subject E was aware of common food sources of iron. Five participants had experienced symptoms of iron deficiency at the time of the study or in the past. Of these, three expressed having made changes in their diet to increase iron intake due to low ferritin levels and/or experiencing symptoms. One additional participant made this change in response to a low ferritin level despite being asymptomatic. Half of the participants expressed increasing their iron intake from dietary sources in response to higher training loads. Only two increased their total energy intake when training was higher.

\section{Discussion}

A key finding was the inadequate energy intake across most participants. This is significant because of the detrimental effects that insufficient energy intake can have on athletes' performance and health. It is a risk factor for iron deficiency and other nutrient deficiencies and can impair recovery and training adaptations.

Subject D - the only participant whose average daily energy intake reached her EER - had the highest ferritin level. This supports previous findings that low energy intake is a risk factor for poor iron status, regardless of iron intake. ${ }^{21}$ Because this was a common theme among all participants aside from Subject D, it is likely that the athletes' low energy intake is a possible cause for their low ferritin level and/or dependence on an iron supplement to maintain an optimal level for performance. This is demonstrated in Figure 1. 


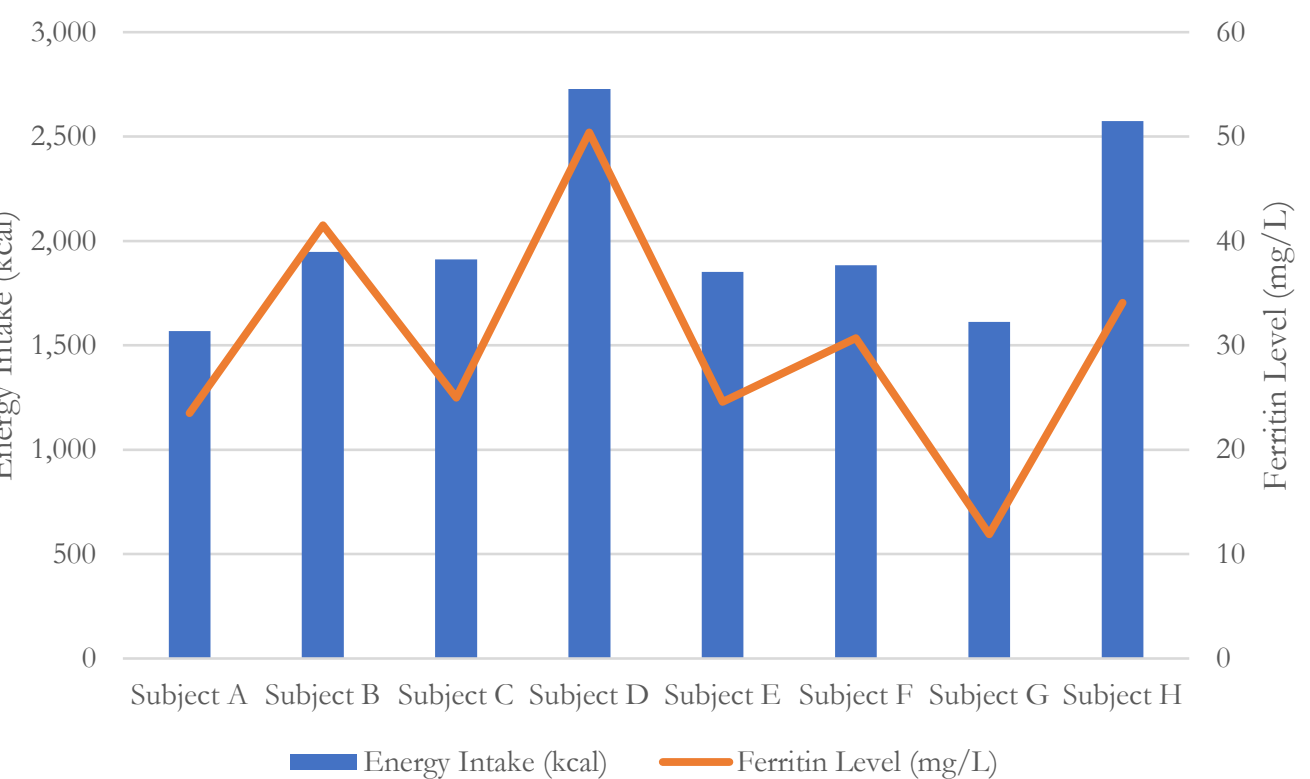

Figure 1. Energy intake versus serum ferritin level in female distance runners

Even while taking a supplement, four athletes experienced low ferritin levels, suggesting that there may be a dietary component contributing to poor iron status. Regardless of the athlete's current ferritin levels, seven participants required iron supplementation due to low ferritin levels at some point in their running careers, suggesting that dietary iron intake is lacking.

Several participants indicated that they focus on the quality of the food they consume rather than the amount. Several specifically mentioned a focus on carbohydrates and protein. This may explain why most participants did not meet their energy requirements. This is important in terms of iron storage given that research has indicated that low energy availability is a risk factor for poor iron status even when iron intake is adequate. ${ }^{21}$

There was a lack of consistency in terms of a correlation between iron intake and iron status which may also be explained by the participants' low energy intake. This is further support for low energy availability being a risk factor for poor iron status and may also be because they would likely consume more iron if they were consuming adequate calories.

Only two participants met the RDA for Vitamin E, so they may benefit from increasing their dietary Vitamin E intake to promote iron absorption. One of only two participants who did not meet the RDA for either Vitamin C or Vitamin E was Subject D, who had the highest ferritin level. This may be because Subject D was the only participant with an adequate energy intake, which may have a protective effect against poor iron status. ${ }^{21}$ The remaining athletes' low energy intake may explain any failure to meet the RDAs for these nutrients.

Aside from its negative effects on iron absorption, calcium is a very important nutrient for runners because of its role in bone health. Half of the participant's met the RDA for calcium and should continue to do so. However, educating athletes on how best to consume adequate calcium while avoiding co-ingestion of calcium and iron may be beneficial to iron absorption.

Furthermore, there did not appear to be any trend in terms of polyphenol containing beverages and ferritin level, nor were any of the athletes lacking in cystine or methionine consumption.

Experiencing symptoms of iron deficiency and/or receiving a low ferritin result in the past was the most common reason for increasing dietary iron, even for those who have never experienced symptoms. Educating athletes on the consequences of poor iron status could be a motivating factor to ensure adequate iron intake. 
Barriers to incorporating dietary iron that were mentioned included being too busy to plan iron rich meals, not preferring red meat, and not having access to iron rich foods. Therefore, providing iron rich foods at practice and/or teaching the athletes simple ways to incorporate dietary iron from a variety of sources could potentially be beneficial.

\section{Limitations and Future Directions}

Because of the small sample size, all trends were purely observational, so it was not possible to know whether there was any statistical significance or conclude any causal effects. The athletes were only representative of one school/team with little diversity, so it is unknown whether these findings would be consistent elsewhere. With athletes who participate in sports where weight and/or aesthetics are perceived to be a contributing factor to performance, underreporting on dietary intake records is common. ${ }^{22}$ Therefore, it is possible that some of the athletes misreported their intake.

Future studies could include a greater number of participants from a variety of schools, regions, races, and ethnicities. This would make the results more generalizable to other teams/individuals. It would also allow for quantitative analysis to determine the statistical significance. Because the most apparent trend across participants was low energy availability, future studies could aim to assess the prevalence of this issue among cross-country runners and explain any barriers that may be causing this issue. This could be important in preventing poor iron status and other nutrient deficiencies and health complications associated with low energy availability. A longitudinal study may also be interesting to assess different points in the season and off-season. Because the data in this study were preexisting, the athletes' menstrual cycles/hormonal status was not included in analysis. However, since a female athlete's menstrual status and/or the use of oral contraceptives can influence iron status, this could be included in future studies. 3,6

\section{Conclusions}

Even though all but one participant was taking an iron supplement at the time of ferritin testing, half tested with low ferritin levels. The other half likely relied on supplementation. This was supported by the consistently low iron and energy intake across participants. Many athletes did not attempt to increase energy intake to accommodate a high training load. Therefore, the importance of overall energy intake should be emphasized. Since all participants were taking an iron supplement, they were meeting the RDA for iron despite most not consuming enough dietary iron, highlighting low energy availability as a risk factor for poor iron status. The importance of adequate energy intake should be included in educational efforts to improve the health and performance of these athletes.

An application of these findings would be education for athletes and coaches on how to improve iron status. The athletes' inability or unwillingness to meet their energy requirements seemed to be slightly alleviated when food was provided at practice by the coaching staff, indicating that energy intake could be improved if recovery nutrition is provided. Education on the importance of adequate energy intake for recovery and protection against iron deficiency should be a priority. This should also include information on how to easily incorporate a variety of iron rich foods under time restrictions and to accommodate taste preferences and accessibility. The potential consequences/symptoms and detrimental effects on performance could be used motivation, as many athletes expressed a desire to alleviate and/or avoid symptoms of iron deficiency.

\section{Media-Friendly Summary}

A study of eight female collegiate cross-country runners revealed that the most lacked dietary sources of iron and overall energy, putting them at risk for poor iron status and possibly explaining their reliance on iron supplementation. For athletes that had attempted to increase dietary iron intake, the main motivating factor was the prevention of deficiency symptoms. When educating these athletes, an emphasis should be placed on the importance of overall energy intake, which will most likely increase the intake of dietary iron and other nutrients that enhance iron absorption.

\section{Acknowledgements}

I want to thank the members of the women's cross-country team for their participation, as well as the coaching and training staff for their help.

\section{References}

1. Blanco-Rojo R, Vaquero, MP. Iron bioavailability from food fortification to precision nutrition. A review. Innov Food Sci Emerg Technol. 2019;51:126-138. doi: 10.1016/j.ifset.2018.04.015

2. Garza D, Shrier I, Kohl HW, Ford P, Brown M, Matheson GO. The clinical value of serum ferritin tests in endurance athletes. J Sport Med. 1997;7(1):46-53. doi: 10.1097/00042752-199701000-00009 
3. Suedekum NA, Dimeff RJ. Iron and the athlete. Curr Sports Med Rep. 2005;4(4):199-202. doi: 10.1097/01.csmr.0000306207.79809.7f

4. Alaunyte I, Stojceska V, Plunkett A. Iron and the female athlete: a review of dietary treatment methods for improving iron status and exercise performance. J Int Soc Sports Nutr. 2015;12(1). doi: 10.1186/s12970-015-00992

5. Beard J, Tobin B. Iron status and exercise. Am J Clin Nutr. 2000;72(2):594-597. doi: 10.1093/ajcn/72.2.594s

6. Zimmermann MB, Hurrell RF. Nutritional iron deficiency. Lancet. 2007;370(9586):511-520. doi: 10.1016/s01406736(07)61235-5

7. World Health Organization (WHO). Archived: Iron deficiency anaemia: assessment, prevention and control. World Health Organization. June 27, 2018. Accessed December, 2019. https://www.who.int/nutrition/publications/micronutrients/anaemia_iron_deficiency/WHO_NHD_01.3/en/

8. Habte K, Adish A, Zerfu D, et al. Iron, folate and vitamin B12 status of Ethiopian professional runners. Nutr Metab. 2015;12(1). doi: 10.1186/s12986-015-0056-8.

9. Anschuetz S, Rodgers CD, Taylor AW. Meal composition and iron status of experienced male and female distance runners. J Exerc Sci Fit. 2010;8(1):25-33. doi: 10.1016/s1728-869x(10)60004-4

10. Coates A, Mountjoy M, Burr J. Incidence of iron deficiency and iron deficient anemia in elite runners and triathletes. Clin J Sport Med. 2017;27(5):493-498. doi: 10.1097/jsm.0000000000000390

11. Rúnarsdóttir TR. Body composition and training levels in relation to iron deficiency among athletes and other physically active individuals [Unpublished master's thesis]. University of Iceland. 2018.

12. U.S. Department of Health and Human Services (HHS) and U.S. Department of Agriculture (USDA). 2015-2020 Dietary Guidelines for Americans. Office of Disease Prevention and Health Promotion. December, 2015. Accessed December, 2019. http://health.gov/dietaryguidelines/2015/guidelines/

13. National Heart Lung and Blood Institute (NHLBI). Serving size card. National Institutes of Health. 2013. Accessed December, 2019. https:// nutritionandaging.org/wp-content/uploads/2013/01/servingcard7.pdf

14. Frankenfield DC. Bias and accuracy of resting metabolic rate equations in non-obese adults. Clin Nutr. 2013;32(6):976-982. doi: https://doi.org/10.1016/j.clnu.2013.03.022

15. Frankenfield DC, Roth-Yousey, L, Compher, C. Comparison of predictive equations for resting metabolic rate in healthy nonobese and obese adults: a systematic review. J Am Diet Assoc. 2005;105(5):775-789. doi: https://doi.org/10.1016/j.jada.2005.02.005

16. Bytomski JR. Fueling for performance. Sports Health. 2018;10(1);47-53.

17. Ly KH, Stanzione JR, Volpe SL. Determining the accuracy of basal metabolic rate prediction equations for athletes.

18. National Science Foundation (NSF). User-friendly handbook for mixed-method evaluations. NSF. August 1997. Accessed December 2019. https://www.nsf.gov/pubs/1997/nsf97153/start.htm

19. Taylor-Powell E, Renner M. Analyzing qualitative data. UW Externsion. 2003. Accessed December, 2019. https://cdn.shopify.com/s/files/1/0145/8808/4272/files/G3658-12.pdf

20. Creswell, JW. Miller, DL. Determining validity in qualitative inquiry. Theory Pract. 2000;39(3):124-130.

21. Burke DE, Johnson JV, Vukovich MD, Kattelmann KK. Effects of lean beef supplementation on iron status, body composition and performance of collegiate distance runners. Food Sci Nutr. 2012;3(6):810-821. doi: 10.4236/fns.2012.36109

22. Logue D. Low energy availability in athletes: A review of prevalence, dietary patterns, physiological health, and sports performance. Sports Med. 2017;48(1):73-96. doi: 10.1007/s40279-017-0790-3 